\section{Pulmonary Vascular Disease \\ P1 CLINICAL AND ECONOMIC BENEFIT OF CARDIOPULMONARY EXERCISE TESTING (CPX) IN PULMONARY HYPERTENSION}

doi:10.1136/thoraxjnl-2011-201054c.1

B Mukherjee, D Sirisena, K Murphy, H Tighe, L Howard. Hammersmith Hospital, Imperial College Healthcare, London, UK

Rationale The exercise response in pulmonary hypertension $(\mathrm{PH})$ has characteristic features, including decreased peak oxygen consumption, increased ventilatory inefficiency (VE/VCO2 slope) and widened alveolar-arterial gradient. These features can be used in diagnosing $\mathrm{PH}$ or distinguishing it from other causes of breathlessness. Many of the measurements from CPX are effort-independent, unlike the 6-min walk test, and can be used to discriminate uncontrolled $\mathrm{PH}$ from other factors which may affect peak capacity, such as obesity. We wished to evaluate the clinical and economic impact of CPX in $\mathrm{PH}$.

Methods We performed a retrospective analysis of 552 studies performed between August 2007 and August 2010. The impact of these tests was assessed by reviewing clinic letters and multidisciplinary team minutes.

Results As a direct consequence of CPX, (1) 69 (13\%) new non-PH diagnoses were made leading to changes in management and non- $\mathrm{PH}$ therapy in 18 (3\%); (2) cardiac catheterisation was avoided in 69 $(13 \%)$ and identified as necessary in $5(1 \%)$, with a net saving of $£ 179.5 \mathrm{k}$; (3) 33 non-PH causes for patients' symptoms were identified, preventing the addition of unnecessary and expensive therapies, saving £318.9k; 4) four patients were identified as needing additional therapy, albeit at greater cost (£26.6k); 5) finally, CPX facilitated confident discharge of patients in 38 (7\%). The total saving using $\mathrm{CPX}$ over 3 years was $£ 457.9 \mathrm{k}$. Appropriate charging structures are not in place for CPX and testing was carried out using research facilities, however, a new national tariff for CPX is set at $£ 235 /$ test. This would still result in net saving of $£ 328.2 \mathrm{k}$ (a gain of $£ 594 /$ test) in addition to the clinical benefit. We identified further savings of $£ 93.6 \mathrm{k}$ which could have resulted from use of CPX earlier in the diagnostic process, increasing the net gain from $£ 594$ to $£ 764$ per test.

Conclusion CPX provides clinical and financial benefit by directing investigations and treatments in a substantial number of cases. CPX prevented patients undergoing expensive and invasive investigations to establish diagnoses and monitor progression. CPX also improved appropriate use of therapies by characterising patients' functional capacity and identifying when alternative conditions were responsible for patients' deterioration.

\section{\begin{tabular}{|l|l}
\hline P2 IN-FLIGHT HYPOXAEMIA IN PATIENTS WITH PULMONARY \\
\hline
\end{tabular} ARTERIAL HYPERTENSION (PAH)}

doi:10.1136/thoraxjnl-2011-201054c.2

R M Burns, A J Peacock, M K Johnson, A C Church. Scottish Pulmonary Vascular Unit, Glasgow, UK

Background and Aim Aircraft travel can worsen hypoxaemia in patients with $\mathrm{PAH}$ since pressurised cabins reduce inspired oxygen $\left(\mathrm{FiO}_{2}\right)$ to the equivalent of breathing $15.1 \%$ at sea level. The British Thoracic Society (BTS) recommends assessing these patients for additional oxygen before air travel, but the criteria used are based on studies of people with COPD (Thorax, 2004). New recommendations, in press, suggest that all patients with $\mathrm{PAH}$ in WHO Functional Class III and IV have in-flight oxygen (Thorax, In Press). The aim of this study was to determine the impact of current and future recommendations on $\mathrm{PAH}$ patients, with the hypothesis that more PAH patients will fail a hypoxic challenge test (HCT) than seen in other respiratory conditions.
Methods Patients with $\mathrm{SpO}_{2}>90 \%$ on air underwent a HCT using a $40 \%$ Venturi mask driven with nitrogen generating an $\mathrm{FiO}_{2}$ of $15.1 \%$. This was stopped after $20 \mathrm{~min}$ or if $\mathrm{SpO}_{2}<85 \%$. Capillary blood gas (CBG) measurements were made at the start and end of HCT. Current criteria suggest that an arterial partial pressure of oxygen $\left(\mathrm{PaO}_{2}\right)<6.6 \mathrm{kPa}$ or a $\mathrm{SpO}_{2}<85 \%$ represents failing the test and in-flight oxygen is needed.

Results Thirty-six patients were recruited: 10 failed (28\%), 26 passed $(72 \%)$. The alveolar-arterial oxygen $(\mathrm{A}-\mathrm{a}) \mathrm{O}_{2}$ gradient significantly fell during the HCT (4.64 vs $1.61 \mathrm{kPa}, \mathrm{p}<0.0001$ [see Abstract $\mathrm{P} 2$ figure 1]). Univariate analysis showed pre-test $\mathrm{SpO}_{2}$ (95 vs 92.5 , $\mathrm{p}=0.027), \mathrm{PaO}_{2}(10.63$ vs $9.15 \mathrm{kPa}, \mathrm{p}=0.0021)$ and $(\mathrm{A}-\mathrm{a}) \mathrm{O}_{2}$ gradient (4.32 vs $5.48 \mathrm{kPa}, \mathrm{p}=0.026$ ) to differ significantly between those who passed and failed. Three patients who failed the HCTwould be missed by current BTS recommendations and one patient would receive in-flight oxygen despite passing the HCT. According to the new recommendations, 15 people would have been given in-flight oxygen who did not require it according to their HCT result.

Conclusions $\mathrm{PAH}$ patients are no more likely to fail a HCT than other respiratory patients. The narrowing of the $(\mathrm{A}-\mathrm{a}) \mathrm{O}_{2}$ gradient during the test may suggest an improvement in $\mathrm{V} / \mathrm{O}$ matching, protecting patients from severe hypoxaemia. Both current and new BTS recommendations missed patients who might require supplementary oxygen, with new recommendations suggesting the need for in-flight oxygen in many patients who do not require it according to the result of their HCT.

\section{(A-a) $\mathrm{O}_{2}$ gradient}

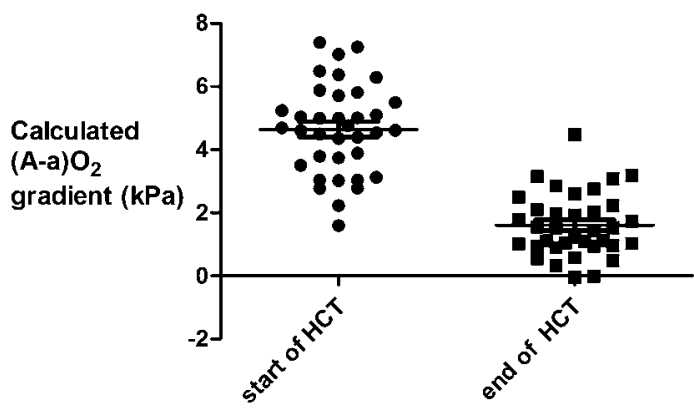

$p<0.0001$

Abstract P2 Figure 1

\section{P3 ARE INFLAMMATORY CYTOKINE LEVELS ALTERED BY TREATMENT OF PULMONARY ARTERIAL HYPERTENSION?}

doi:10.1136/thoraxjnl-2011-201054c.3

G Hagan, M Southwood, C Treacy, K Sheares, N Morrell, J Pepke-Zaba. Pulmonary Vascular Disease Unit, Papworth Hospital, Papworth Everard, UK

Introduction and Objectives Markers of immune activation and inflammation are raised in pulmonary arterial hypertension; the degree of elevation of levels of pro-inflammatory cytokines in idiopathic pulmonary arterial hypertension has recently been shown to predict long term survival (Soon et al, Circulation, 2010). Much less is known of the role of cytokines in disease monitoring. We assessed levels of serum cytokines in patients at initial assessment prior to commencement of targeted therapy for pulmonary hypertension, and when the patient returned to the hospital for follow-up. We also examined if changes in serum cytokines correlated with changes in 6-min walk test (6MWT).

Methods 19 patients with a diagnosis of Group I PAH or Group IV chronic thromboembolic pulmonary hypertension in a distribution inaccessible to surgery were included. Patients with inflammatory conditions other than an associated connective tissue disease or a musculoskeletal condition that would interfere with the 6MWT 